\title{
Role of Allergy, Respiratory Infection, and Passive Smoking in Early Onset Adenotonsillar Hypertrophy
}

\author{
Sami AlHarethy ${ }^{1 *}$, Ibrahim Alarifi ${ }^{2}$, Hisham Almutawa ${ }^{3}$ and Tahera Islam ${ }^{4}$ \\ ${ }^{1}$ Department of Otolaryngology-Head and Neck Surgery, College of Medicine, King Saud University, Saudi Arabia \\ ${ }^{2}$ Department of Otolaryngology-Head and Neck Surgery, Security Forces Hospital, Saudi Arabia \\ ${ }^{3}$ Otorhinolaryngology Head and Neck Surgery Section, Department of Surgical Specialities, Saudi Arabia \\ ${ }^{4}$ College of Medicine and Research center, King Saud University, Saudi Arabia
}

Submission: July 07, 2017; Published: July 14, 2017

*Corresponding author: Sami AlHarethy, Department of Otolaryngology-Head and Neck Surgery, College of Medicine, King Saud University, Riyadh 11411, Kingdom of Saudi Arabia, Saudi Arabia, Email: samiharthi@gmail.com

\begin{abstract}
Objective: The aim of this study was to examine the relationship between allergic diseases and the time of Adenotonsillar Hypertrophy (ATH) onset. We also investigated whether there is any relationship between upper respiratory tract infection (URTI) or exposure to parental smoking and ATH.

Methods: A cross sectional study was conducted in multiple tertiary care centers. We interviewed all parents of subjects aged 1 month to 15 years admitted for adenotonsillectomy from January 2016 to January 2017. The parents were asked questions regarding the time of ATH-related symptom onset, demographic information, allergic history of the child and parents, frequency of URTI, and passive smoking.

Results: There were 252 subjects, and the mean age $( \pm \mathrm{SD})$ was $5.91 \pm 3.02$ years. The data indicate $63.1 \%$ of the early onset group had a significant personal history of allergy. In the late onset group, the incidence was $55.9 \%(p=0.261)$. Additionally, $64.1 \%$ of the early onset group subjects had a parental history of allergy. In the late onset group $64.7 \%$ of subjects had a parental history of allergy $(p=0.920)$. Only $8.7 \%$ of early onset group and $8.1 \%$ of late onset group were exposed to parental smoking $(p=0.857)$. The incidence of subjects who had URTIs $1-3$ times/year was $18.8 \%$ in the early group and $32.6 \%$ in the late onset group. The incidence of subjects who had URTIs $4-6$ times/year was $35.6 \%$ and $30.3 \%$ respectively. The rates of subjects with more than 6 URTIs per year were $45.5 \%$ and $37.1 \%$ respectively $(p=0.038)$. In the early onset group the frequency of subjects with atopic dermatitis, bronchial asthma, and food allergy was higher than in the late onset group $(p=0.349,0.11,0.015$ respectively). However, the frequency of subjects with allergic rhinitis, allergic conjunctivitis and parental allergy was lower than that in the late onset group ( $p=0.381,0.138,0.920$ respectively).
\end{abstract}

Conclusion: Our data indicate only food allergy was significantly associated with early onset ATH. We also found higher frequencies of UTRIs are associated with a higher incidence of ATH.

Abbreviations: ATH: Adenotonsillar Hypertrophy; URTI: upper respiratory tract infection; RAST: Radio Allergosorbent Test; AR: Allergic Rhinitis; AC: Allergic Conjunctivitis; AD: Atopic Dermatitis; BA: Bronchial Asthma; FA: Food Allergy

\section{Introduction}

Adenoids and palatine tonsils and the tubal and lingual tonsils compose Waldeyer's ring [1], which produces antigens to environmental allergens [2]. Adenotonsillar hypertrophy (ATH) has burdened families for decades; it is the most common cause of airway obstruction and obstructive sleep apnea in the pediatric age group $[3,4]$. ATH is associated with serious consequences, such as developmental delays in children [5], right heart failure and corpulmonale [6,7]. In addition, ATH is a leading cause of clinic visits and hospital admissions in this age group [8]. Adenotonsillectomy is considered the most common procedure in otolaryngology [9].
Infections remain the most common cause of enlargement of adenoids and/or tonsils. However, the role of allergies has not been examined as a cause of adenotonsillar hypertrophy. Sadeghi-Shabestari et al. [10] evaluated 217 children with ATH and allergy and found $70.3 \%$ of the study group had positive skin prick test results. Conversely, only $10 \%$ of the control group had positive skin prick test results. Similarly, Olusesi et al. [11] reported that a family history of allergies and personal allergy history were related to early onset ATH in Nigerian children. Similar results were found among Polish children in three studies by Modrzyński et al. [12-14] who concluded that allergy 
is considered a risk factor for ATH. The prospective cohort study by Griffin et al. found that $21 \%$ of the study group had positive radio allergosorbent test (RAST) results and 20\% in the control group had positive test results [15]. Moreover, the study in Brazil by Costa et al showed $37 \%$ of adenoid hypertrophy patients were allergic and $33 \%$ of tonsillar hypertrophy cases were allergic [16].

The study by Rajeshwary et al. [17] concluded that "infection is the main cause of adenoid hypertrophy". Faden et al reported that subclinical viral infections are more common in adenoids than tonsils [18]. Sadeghi-Shabestari et al. [10] reported passive smoking was associated with adenoid hypertrophy. Furthermore, Evcimik et al. [19] concluded that passive smoking is a risk factor for developing adenoid hypertrophy. The objective of our study was to examine the relationship between allergic diseases and the time of ATH onset. In addition, we investigated whether there is any relationship between upper respiratory tract infections (URTI) or exposure to parental smoking and ATH.

\section{Materials and Methods}

A cross sectional study was conducted in multiple tertiary care centers (King Abdulaziz University Hospital, Security Forces Hospital, and Prince Sultan Military Medical City) in Riyadh, Saudi Arabia. We interviewed the parents of subjects who were admitted for adenotonsillectomy from January 2016 to January 2017. Our inclusion criteria were subjects aged from 1 month to 15 years who were confirmed to have ATH during the clinic visit using a combination of clinical presentation and the physical examination. We used a flexible fiberoptic nasopharyngoscope to diagnose the adenoid hypertrophy. The Brodsky scale was used to diagnose tonsillar enlargement. We excluded subjects with genetic syndromes and craniofacial anomalies.

A questionnaire was completed by an otolaryngology resident and consisted of the following 4 parts:

a. Demographic information including age, gender, and the age ATH symptoms were first noticed.

b. Allergic history in the child and his/her parents including allergic rhinitis (AR), allergic conjunctivitis (AC), atopic dermatitis (AD), bronchial asthma (BA), and food allergy (FA).

\section{c. Frequency of URTI per year. \\ d. Presence of passive smoking.}

The ATH symptoms included snoring, mouth breathing, sleep disturbance, witnessed sleep apnea, and recurrent tonsillitis. We also obtained information on the symptoms of AR (sneezing, itching, and watery rhinorrhoea), AC (eye itching and redness), $\mathrm{AD}$ (skin itching and redness), BA (usage of bronchodilators and previous diagnosis), and FA in the child and his/her parents. These results were considered the personal and parental history of allergy, respectively. We categorized the patients into 3 groups based on the annual frequency of URTI: 1-3 times / year, 4-6 times / and $>6$ times / year. We divided our subjects into early and late ATH onset based on the age symptoms developed. We defined the early onset group as having symptoms starting at or before the age of 12 months because 2-5 years is the average age of the normal physiological adenotonsillar enlargement $[20,21]$. The definition of late onset ATH was symptoms presenting after the age of 12 months. All data were entered and analyzed using IBM SPSS Statistics 23.0.

\section{Results}

There were 260 subjects interviewed in the hospital during their admission period in a comfortable and private environment. There were four males and two females excluded from the study. Thus, 252 subjects met our inclusion criteria, and the patient cohort consisted of 154 males and 98 females. The patient age range was 14 months to 15 years. In our study population, $61.1 \%$ of subjects were males and $38.5 \%$ were females, and the male to female ratio was $1.6: 1$. The mean ages at the time symptom onset for males and females were $2.39 \pm 2.23$ years and $2.99 \pm$ 2.53 years, respectively. The mean age at surgery was $5.91 \pm 3.02$ years for males and $6.78 \pm 3.29$ years for females (Table 1 ).

Table 1: Demographic characteristics.

\begin{tabular}{|c|c|c|}
\hline Gender N (\%) & $\begin{array}{c}\text { Mean age at } \\
\text { symptom onset } \\
\text { Mean } \pm \text { SD }\end{array}$ & $\begin{array}{c}\text { Mean age at time of } \\
\text { surgery Mean } \pm \text { SD }\end{array}$ \\
\hline $\begin{array}{c}\text { Male } \\
146(61.1)\end{array}$ & $2.389 \pm 2.231$ & $5.908 \pm 3.0228$ \\
\hline $\begin{array}{c}\text { Female } \\
93(38.9)\end{array}$ & $2.998 \pm 2.533$ & $6.775 \pm 3.287$ \\
\hline Total & $6.254 \pm 3.148$ & $6.254 \pm 3.148$ \\
\hline
\end{tabular}

Table 2: The mean age at onset in association with personal and paternal history of allergy, passive smoking, and frequency of upper respiratory tract infection (URTI).

\begin{tabular}{|c|c|c|c|c|}
\hline & & \multicolumn{2}{|c|}{ Age of onset } & \multirow{2}{*}{$p$-value } \\
\hline & & $\leq 1$ year & $>1$ year & \\
\hline \multirow{2}{*}{$\begin{array}{l}\text { Personal history of } \\
\text { allergy }\end{array}$} & $+\mathrm{ve}$ & $65(63.1 \%)$ & 76 (55.9\%) & \multirow{2}{*}{0.261} \\
\hline & -ve & $38(36.9 \%)$ & $60(44.1 \%)$ & \\
\hline \multirow{2}{*}{$\begin{array}{c}\text { Parental history of } \\
\text { allergy }\end{array}$} & + ve & $66(64.1 \%)$ & $88(64.7 \%)$ & \multirow{2}{*}{0.920} \\
\hline & -ve & $37(35.9 \%)$ & $48(35.3 \%)$ & \\
\hline \multirow{2}{*}{ Passive smoking } & $+\mathrm{ve}$ & $9(8.7 \%)$ & $11(8.1 \%)$ & \multirow{2}{*}{0.857} \\
\hline & -ve & $94(91.3 \%)$ & $125(91.9 \%)$ & \\
\hline \multirow{3}{*}{ URTI } & 1 to 3 & $19(18.8 \%)$ & $43(32.6 \%)$ & \multirow{3}{*}{0.038} \\
\hline & 4 to 6 & $36(35.6 \%)$ & $40(30.3 \%)$ & \\
\hline & $>6$ & $46(45.5 \%)$ & $49(37.1 \%)$ & \\
\hline
\end{tabular}

Table 2 demonstrates the rates of both early and late onset groups with respect to personal history of allergy, parental history of allergy, passive smoking, and frequency of URTIs. The data indicate $63.1 \%$ of the early onset group had a significant personal history of allergy and $55.9 \%$ of cases in the late onset 
group had a history of allergy ( $p=0.261$ ). Our results also show $64.1 \%$ of the early onset group subjects reported a parental history of allergy and $64.7 \%$ of the late onset group subjects had a parental history of allergy ( $p=0.920)$. Only $8.7 \%$ of early onset group and $8.1 \%$ of late onset group were exposed to parental smoking ( $p=0.857)$. The rates of subjects who had URTIs 1-3 times/year in the early and late onset groups were $18.8 \%$ and $32.6 \%$, respectively. The data show the percentages of subjects with URTIs 4-6 times / year in the early and late onset groups were $35.6 \%$ and $30.3 \%$ respectively. The rates of and subjects with URTIs more than 6 times/year in the early and late onset groups were $45.5 \%$ and $37.1 \%$, respectively ( $p=0.038$ ).

Figure 1 separates the early and late onset groups into 4 subgroups:

a. No personal or paternal history of allergy,

b. History of personal allergy,

c. Parental history of allergy, and

d. both personal and parental history of allergy.

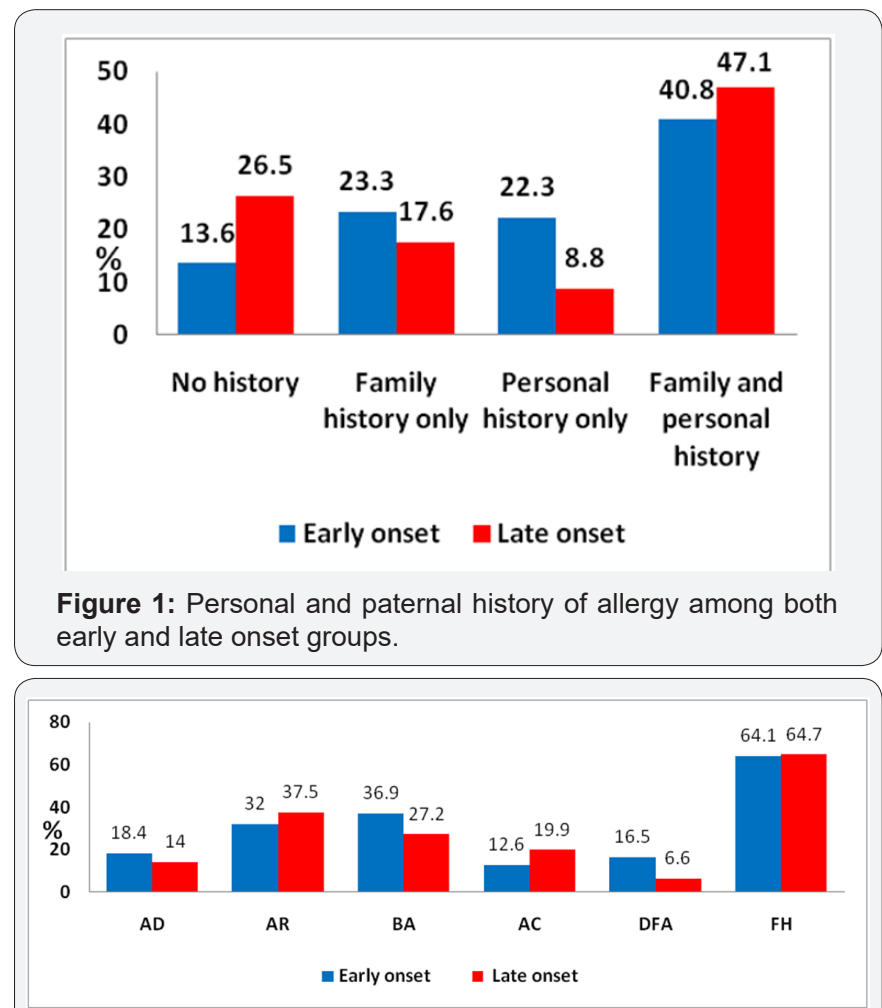

Figure 2: Percentages of different allergic diseases in the early and late onset groups. (AD: atopic dermatitis, AR: allergic rhinitis, BA: bronchial asthma, AC: allergic conjunctivitis, FA: food allergy, $\mathrm{PH}$ : paternal history).

Figure 2 demonstrates the percentage of each of the personal allergic diseases (AD, AR, BA, AC, and $\mathrm{FA}$ ) and the paternal history of allergy in the early and late onset groups. The early onset group had a higher frequency of subjects with $\mathrm{AD}, \mathrm{BA}$, and FA than the late onset group ( $p=0.349,0.11,0.015$ respectively).
Conversely, the frequency of subjects with AR, AC and paternal history of allergy was lower than the late onset group ( $p=0.381$, 0.138 , and 0.920 , respectively).

The mean age $( \pm$ SD) of subjects with BA was $2.49( \pm 2.37)$ years and the mean age of subjects with no BA was $2.69( \pm 2.36)$ years. The subjects with AD had a mean age of $2.38( \pm 2.26)$ years and the mean age of cases without AD was $2.67( \pm 2.38)$ years. The mean age of the subjects with FA was $2.14( \pm 2.40)$ years and the mean age of the subjects without FA was $2.69( \pm 2.35)$ years. The subjects with AR had a mean age of $2.73( \pm 2.33)$ years and the subjects without AR had mean age of $2.57( \pm 2.38)$ years. Furthermore, the mean age of subjects with AC was 2.92 (2.41) years, and the mean age of the subjects without AC was 2.57 $( \pm 2.35)$ years. Lastly, subjects with a parental history of allergy had mean age of $2.65( \pm 2.27)$ years and the subjects without any parental history had mean age of $2.59( \pm 2.52)$ years.

Table 3 demonstrates the rates of subjects in the early onset group with any personal or parental history of allergy, exposure to cigarette smoke and URTIs. We found $63.1 \%$ of cases had a personal history of allergy ( $p=0.01)$ and $64.1 \%$ had a paternal history of allergy $(p=0.006)$. Furthermore, only $8.7 \%$ were exposed to cigarette smoke $(\mathrm{p}<0.0001)$. The URTI data show $18.8 \%$ of cases had infections $1-3$ times/year, $35.6 \%$ of cases had infections $4-6$ times/year, and $45.5 \%$ of cases had infections more than 6 times/year $(p=0.004)$.

Table 3: Early onset subjects in regard of personal and paternal history of allergy, passive smoking, and frequency of upper respiratory tract infection (URTI).

\begin{tabular}{|c|c|c|}
\hline & Age at onset Early ( $\leq$ year) & p-value \\
\hline $\begin{array}{c}\text { Personal Allergy } \\
\text { History } \\
\text { +ve } \\
\text {-ve }\end{array}$ & $\begin{array}{c}65(63.1 \%) \\
\text { 38 (36.9\%) }\end{array}$ & 0.01 \\
\hline $\begin{array}{c}\text { Paternal Allergy History } \\
\text { +ve } \\
\text {-ve }\end{array}$ & $37(35.9 \%)$ & 0.006 \\
\hline $\begin{array}{c}\text { Passive Smoking } \\
\text { Yes } \\
\text { No }\end{array}$ & $9(8.7 \%)$ & $<$ \\
\hline $\begin{array}{c}\text { Number of URTI attacks / } \\
\text { year } \\
\text { to 3 }\end{array}$ & $19(18.8 \%)$ & 0.0001 \\
4 to 6 & $36(35.6 \%)$ & 0.004 \\
\hline$>6$ & $46(45.5 \%)$ & \\
\hline
\end{tabular}

\section{Discussion}

Waldeyer's ring is a lymphatic structure in the area of nasopharynx and oropharynx. The structure consists of adenoid, two tubal tonsils, two palatine tonsils, and lingual tonsil [1]. ATH is rarely found in infants less than 1-year of age [22] because maternal antibodies protect infants from bacterial infections until the age of 6-12 months [23-28]. However, previous studies have reported ATH onset at 6, 12 and 18 months [11,23,29]. 
Therefore, we defined the early onset as symptoms starting at or before the age of 12 months. In this study, we found children who were diagnosed with early onset ATH tend to have AD, BA, and FA more frequently than the late onset subjects. However, only FA was statistically significant. Sadeghi-Shabestari [10] found $70.3 \%$ of the ATH group had a positive skin prick test and $48 \%$ of cases had high total IgE levels. In contrast, only $10 \%$ of control group had positive skin prick test results. The majority of subjects with positive skin prick test results were allergic to food. The study was conducted in children aged from 1 to 15 years without specifying early or late onset ATH.

Alexopoulos et al. used physician-diagnosed eczema as the primary variable in all pediatric age groups and found it was not significantly associated with the presence of ATH [22]. However, Costa et al concluded there was no direct correlation between atopy and the extent of enlarged tonsils and adenoids in the mouth breathing patients evaluated. The authors found $46 \%$ of mouth breathing children had adenoid hypertrophy and $37 \%$ of these patients were atopic. Additionally, $47 \%$ had tonsillar hypertrophy, and $33 \%$ of these patients were atopic based on the skin prick test [16]. We observed the mean ages at the time of ATH-related symptom onset in subjects with AD, BA and FA were lower than those without symptoms. However, the differences were not statistically significant. The subjects with allergies present earlier than those with AC, AR, or PA. Olusesi et al. [11] found subjects with AD and a family history of allergy tend to have earlier onset of ATH (at the age of 6 months or less) compared to subjects with BA and AR.

Rajeshwary et al. [17] observed that aerobic pathogens grew in $93 \%$ of the specimens and anaerobic pathogens in $68 \%$ of specimens. However, $7 \%$ had no growth, and the authors concluded the main cause of adenoid hypertrophy is infections. In our study, we categorized our population based on frequency of URTI into 3 groups: 1-3 times/year, 4-6 times / year and >6 times / year. We found that as the number of URTIs increased the risk of having ATH increased, and the difference was statistically significant. Faden et al. [18] reported that viruses were detected in $70.9 \%$ of tonsils and $94.7 \%$ of adenoids in their study population. Evcimik et al found that exposure to cigarette smoking was more common in subjects with adenoid hypertrophy $(\mathrm{AH})$. In the $\mathrm{AH}$ group $62.2 \%$ of cases had exposure to cigarette smoke and in the group without $\mathrm{AH} 49.7 \%$ had exposure to cigarette smoke [29]. Moreover, Sadeghi-Shabestari et al. [10] reported children with smoking caretakers had a higher risk for ATH. In the group with positive skin prick test (SPT) results $48 \%$ of cases had smoking caretakers. Conversely, in the group with a negative SPT only $5 \%$ had smoking caretakers. In our study, 9 subjects in the early onset group and 11 subjects in the late onset group were exposed to cigarette smoke. Although this difference cannot be clinically evaluated, we found it was a statistically significant protective factor.
In our study, the history of allergic diseases was based on the history taken from their parents rather than objective measures. Thus, we recommend further studies comparing the early and late onset ATH based on objective skin prick or serological tests. Additionally, food allergy may be a risk factor for early development of ATH. We advise the parents to identify the foods that cause allergy in their infants and recommend not feeding these foods to the child. We could not assess the association of smoking with ATH, and we recommend further studies to address this relationship.

\section{Conclusion}

We conclude that in subjects with any history of allergic diseases only food allergy has a significant association with early onset ATH and may predict it. We also found higher frequencies of UTRIs are associated with higher incidence of ATH

\section{References}

1. Hellings P, Jorissen M, Ceuppens J L (1999) The Waldeyer's ring. Acta oto-rhino-laryngologicabelgica 54(3): 237-241.

2. Masieri S, Trabattoni D, Incorvaia C, De Luca MC, et al. (2014) A role for Waldeyer's ring in immunological response to allergens. Current medical research and opinion 30(2): 203-205.

3. Niedzielska G, Kotowski M, Niedzielski A (2008) Assessment of pulmonary function and nasal flow in children with adenoid hypertrophy. International journal of pediatric otorhinolaryngology 72(3): 333-335.

4. Gislason T, Benediktsdottir B (1995) Snoring, apneic episodes, and nocturnal hypoxemia among children 6 months to 6 years old: an epidemiologic study of lower limit of prevalence. Chest 107(4): 963966.

5. Soylu E, Soylu N, Polat C, Sakallıoğlu Ö, Uçur Ö, et al. (2015) Developmental delays in preschool children with adenotonsillar hypertrophy. Kulak burunbogazihtisasdergisi: $\mathrm{KBB}=$ Journal of ear, nose, and throat 26(3): 129-134.

6. Brown OE, Manning SC, Ridenour B (1988) Cor pulmonale secondary to tonsillar and adenoidal hypertrophy: management considerations. International journal of pediatric otorhinolaryngology 16(2): 131-139.

7. Koc S, Aytekin M, Kalay N, Ozcetin M, Burucu T, et al. (2012) The effect of adenotonsillectomy on right ventricle function and pulmonary artery pressure in children with adenotonsillar hypertrophy. International journal of pediatric otorhinolaryngology, 76(1): 45-48.

8. Ersoy B, Yücetürk AV, Taneli F, Ürk V, Uyanik BS (2005) Changes in growth pattern, body composition and biochemical markers of growth after adenotonsillectomy in prepubertal children. International journal of pediatric otorhinolaryngology 69(9): 1175-1181.

9. Manickavasagam J, Ali S, Quraishi MS (2012) General practitioners' versus consultants' perspective on indications for paediatric tonsillectomy: current trends. The J Laryngol Otol 126(2): 163-167.

10. Sadeghi-Shabestari M, Moghaddam YJ, Ghaharri H (2011) Is there any correlation between allergy and adenotonsillar tissue hypertrophy? International journal of pediatric otorhinolaryngology 75(4): 589-591.

11. Olusesi AD, Undie NB, Amodu JE (2013) Allergy history as a predictor of early onset adenoids/adenotonsillar hypertrophy among Nigerian children. Int j pediatr otorhinolaryngol, 77(6), 1032-1035. 
12. Modrzyński M, Zawisza E (2002) Frequency of adenoid hypertrophy in children with allergic diseases. Przegladlekarski 60(5): 322-324.

13. Modrzyński M, Mazurek H, Zawisza E (2017) Allergic tonsillitis: myth or reality. Journal cover: 71.

14. Modrzyński M, Mierzwiński J, Zawisza E (2003) The occurrence of food allergy and bacteria allergy in chiidren with tonsilar hypertrophy. Przegladlekarski 61(12): 1330-1333.

15. Griffin JL, Ramadan HH, Adham RE (1994) Prevalence of IgE-mediated hypersensitivity in children with adenotonsillar disease. Arch of Otolaryngol Head Neck Surg, 120(2): 150-153.

16. Costa EC, Sabino HAC, Miura CS, de Azevedo CB, et al. (2013) Atopy and adenotonsillar hypertrophy in mouth breathers from a reference center. Braz j of otorhinol 79(6): 663-667.

17. Rajeshwary A, Rai S, Somayaji G, Pai V (2013) Bacteriology of symptomatic adenoids in children. N Ame j med sci 5(2) 113.

18. Faden H, Callanan V, Pizzuto M, Nagy M (2016) The ubiquity of asymptomatic respiratory viral infections in the tonsils and adenoids of children and their impact on airway obstruction. International Journal of Pediatric Otorhinolaryngology 90: 128-132.

19. Evcimik MF, Dogru M, Cirik AA, Nepesov MI (2015) Adenoid hypertrophy in children with allergic disease and influential factors. Int j pediatr otorhinolaryngol 79(5): 694-697.

20. Hui S, Wing YK (1997) Obstructive sleep apnoea syndrome in children. hong kong medical journal 3(4): 419-426.
21. Gaultier C (1995) Sleep-related breathing disorders. 6. Obstructive sleep apnoea syndrome in infants and children: established facts and unsettled issues. Thorax, 50(11): 1204-1210.

22. Alexopoulos EI, Bizakis J, Gourgoulianis K, Kaditis AG (2014) Atopy does not affect the frequency of adenotonsillar hypertrophy and sleep apnoea in children who snore. Acta Paediatrica 103(12): 1239-1243.

23. Shatz A (2004) Indications and outcomes of adenoidectomy in infancy. Annals of Otology, Rhinology \& Laryngology 113(10) 835-838.

24. Winkelstein JA, Marino MC, Lederman HM, Jones SM, et al. (2006) $\mathrm{X}$-linked agammaglobulinemia: report on a United States registry of 201 patients. Medicine 85(4): 193-202.

25. Leuridan E, Hens N, Hutse V, Aerts M (2011) Kinetics of maternal antibodies against rubella and varicella in infants. Vaccine 29(11): 2222-2226.

26. Leuridan E, Van Damme P (2007) Passive transmission and persistence of naturally acquired or vaccine-induced maternal antibodies against measles in newborns. Vaccine 25(34): 6296-6304.

27. Kılıç A, Altınkaynak S, Ertekin V, Inandı T (2003) The duration of maternal measles antibodies in children. J trop pediatr49(5): 302-305.

28. Watanaveeradej V, Endy TP, Samakoses R, Kerdpanich A, et al. (2003) Transplacentally transferred maternal-infant antibodies to dengue virus. Am j tropi med and hyg 69(2): 123-128.

29. Greenfeld M, Tauman R, DeRowe A, Sivan Y (2003) Obstructive sleep apnea syndrome due to adenotonsillar hypertrophy in infants. Int j pediatr otorhinolaryngol 67(10): 1055-1060.

\section{Your next submission with Juniper Publishers will reach you the below assets}

- Quality Editorial service

- Swift Peer Review

- Reprints availability

- E-prints Service

- Manuscript Podcast for convenient understanding

- Global attainment for your research

- Manuscript accessibility in different formats

( Pdf, E-pub, Full Text, Audio)

- Unceasing customer service

Track the below URL for one-step submission https://juniperpublishers.com/online-submission.php 